\title{
Erratum to: Designing an algorithm for evaluating decision-making units based on neural weighted function
}

\section{R. Saneifard}

(C) Springer-Verlag London Limited 2012

\section{Erratum to: Neural Comput \& Applic}

DOI 10.1007/s00521-012-0878-5

In the original publication, under the section "An Application", two paragraphs with figures have been replicated from article "Anteriority index for managing fuzzy dates in archaeological GIS" published in "Soft Computing" journal.

The author apologizes for his mistake and has provided the below replacement text for section "An Application":

\section{An application}

The present study aimed at designing a new map to simulate the archaeological hypothesis on dating. In this respect, this study lend support to the finding from previous study, which used the comparison decisions for spatial inference by using anteriority index [19] in resulting the calculation of the values of the anteriority index between $F$ and $G$, which gave $I(F \cdot G)=0.95$ and $I(G \cdot F)=0.05$. Moreover, the finding of our study indicated the calculation of the value of the anteriority index between $F$ and $G$, by presenting $\mathrm{PD}_{2}\left(F, x_{\max }\right)=0.82$ and $\mathrm{PD}_{2}\left(G, x_{\max }\right)=0.14$. Therefore, $F$ is rather anterior to $G$.

The online version of the original article can be found under doi:10.1007/s00521-012-0878-5.

R. Saneifard $(\bowtie)$

Department of Applied Mathematics, Urmia Branch,

Islamic Azad University, Oroumieh, Iran

e-mail: srsaneeifard@yahoo.com 